\title{
Study on Talents demand and Cultivation Strategy under the "One Belt and One Road"
}

\author{
Gao Yinchun * \\ School of Public Management \\ Yunnan University of Finance and Economics \\ Kunming, China \\ gaoych521@foxmail.com
}

\author{
Ma Keji \\ School of Public Management \\ Yunnan University of Finance and Economics \\ Kunming, China \\ gaoych521@foxmail.com
}

\begin{abstract}
One belt, one road" is the strategic plan based on the current national conditions of China, which greatly increased China's employment opportunities while at the same time the overall quality of talents are put forward new and higher requirements. Under the background of this strategy, this paper carried on the thorough analysis and discussion of different types of talents demand such as language, professional skills, academic exchanges, transnational management and the traditional culture dissemination exchanges, thus on the basis of language and cultural study, put forward the combination of comprehensive and professional high-level talent cultivation countermeasures and the suggestions.
\end{abstract}

Keywords- "One belt, one road"; talent demand; talent training

\section{INTRODUCTION}

"One belt, one road" strategy was put forward by China's chairman Xi in 2013 named "Silk Road Economic Belt" and "the Twenty-first Century Maritime Silk Road", which is the continuation of the ancient trade routes in China and will also build a new opening pattern of East and West mutual as well as co-ordination of land and sea. After this strategy put forward, a lot of scholars in our country have given many thinking in their professional field about talent support, such as some scholars presented navigation professional college students should accept the Values Education[1]; Some scholars put forward our country higher vocational education collaborative innovation talent training mode [2]; "Domestic undergraduate + foreign Master" mode of Long Changhai is a new exploration of foreign legal personnel training mode, and implemented specifically based on geographical advantage and subject advantage [3].These studies concentrate on professional fields more than the cultural and language fields. This paper analyzes the needs of different types of talents in detail and puts forward the corresponding suggestions.

"one road' have their own unique characteristic and complexity, so our talents should consider these factors seriously. And also our country needs to foster different practical talents according to different Cooperative objects. With the further development of the policy, the relation and interaction between the countries along are intensified. All walks of life were also facing the opportunities and challenges of internationalization, which requires our country grasp the

\footnotetext{
* Corresponding author
}

traditional domestic market fully and pay attention to the international market as well as global trends. As a result, the needs of talents naturally are more emphasis on the training of the compound international talents. Countries along "One belt,

\section{NEEDS OF ALL KINDS OF TALENT}

In response to development strategy of "One belt, one road", not only need the institutions which have responsibility of cultivating talents such as universities to make corresponding adjustments in teaching plan, but also all enterprises and social organizations need to make action, such as support the teaching of university. Of course, the talents of other fields also should be fostered.

\section{A. Language Talent}

Communication, understanding and acceptance are the foundation of any strategic policy's implementation, thus the language learning carries all of this is particularly important, and personnel training of language becomes one of basis jobs of talent needs and training. Not only the language professional talents need, but also the persons in other areas of work need to learn the basic communication skills. But according to the statistics, the 175 countries which established diplomatic relations with China have about 95 different languages. But China can only offer 54 language courses. [4] The requirement language here is the languages of the countries along "One belt, one road", which is called small languages by China. The language situation in our country now is not optimistic, because about $90 \%$ of the people have learned the English. However, less of them learned other languages and minority languages. Therefore, the talents in these areas are extremely insufficiency.

\section{B. Professional and Technical Personnel}

Professional and technical personnel are the professionals who related to specific work fields except the language. Excepting their own professional knowledge, these professional various work fields should also have basic abilities to communicate with local people of another country use local language and know local customs, religion, taboos, etc. to consult and exchange their ideas espalier. 


\section{Transnational Management Personnel}

Management personnel are essential talents of all staff management. Management is invisible skill. Management personnel are the coordinator and helm who ensure the normal operation of a business organization. Therefore, it is necessary to develop a large number of management talents with strong management ability and rich experiences in the management of transnational management to ensure the overall strategy's sustainable and steady furtherance.

\section{Academic Research and Exchange Talents}

One of the areas of academic research has always been the international community of the most concern. The place of study is a collection of human wisdom and divergence. The wisdom of the every single person and every single national is limit, therefore, the culture of human's history, sciences and technology need to learn from each other. This area is favored always by the most of the world's academic researchers to make friends with each other. The economic development and the political of the most countries along The Belt and Road will be affected. And also China shares the academic research to these countries, and solve practical problems combine the local actual situation. So our country carries the responsibility to help the small brothers. As the partner country, we also implement the principle of reciprocity. So these qualified talents also need careful selection and training.

\section{E. Traditional Culture Communication Talents}

All of the workers engaged in this strategy must harbor both patriotic idea and international concept and play their value in the whole strategic project. They should remember the idea of our country about friendly cooperation, mutual reciprocity and mutual benefit principle. Therefore, companies and personal shoulder this dual task, namely labor workers and the transmitters of concept.

\section{Personnel Training Mode}

\section{A. Language Talent Training of Target Cooperation Country}

In the early of "The Belt and Road" strategy fully implemented, with the urgent demand for talent and people on the occasion, a pressing matter of the moment can take two ways to solve:

1) Adjust present talents: The present talents who have learnt corresponding required languages can be adjusted to "One belt, one road" planning should be appropriate to do some adjustment. According to the existing talent personal background and work environment, the government should provide participatory adjustment to supplement short board of talent needed quickly. Certainly, it should firstly seek and respect for their personal and companies' views. If these people just familiar with language, but are lack of foreign countries' conventions, cultures, values and other knowledge, the government and the corresponding enterprises should give their study opportunities to let the whole strategy implement more smoothly.

2) Cultivate language talents: Cultivation of these talents needs to join schools and society. School training can be divided into two parts, after college and before university. The high school and even primary school should stage the world language settings as elective courses and during language teaching the cultural knowledge should be penetrated.

Pay more attention to language learning of graduate students and doctoral students, because during this period their language learning ability, comprehension ability and cognitive ability are just at a higher level, thus they learn language relatively faster than other period of the age. Those nonlinguistic majors can match language teaching with the corresponding professional, and try to explore the personnel training mode of "foreign language $+X$ "[5]. About the professional language talents training, it is crucial to adjust existing teaching mode and curriculum setting in colleges and universities which have concentrated on professional knowledge teaching. At the same time, these colleges and universities should focus on the comprehensive study such as language culture, history, customs, habits, religion and so on. In addition, the study abroad joint training and combined with teaching is also encouraged. In practice, "the work and study's combination" is the most favorable way for language learning. $\mathrm{Gu}$ Xiaonan put forward the organization and management teaching form cold "work and study's alternation" for business English majors [6]. He thinks that such practice can not only strengthen the knowledge of students, but also can promote school and enterprise's cooperation, so as to provide training ground for "The Belt and Road" intellectual support.

The introduction of foreign students and foreign personnel can service "One belt, one road" strategy. These people have in-depth knowledge and understanding for the local people and economic development, thus can communicate and cooperate well with the local people. So it's very favorable for the total policy's communication and implementation of China The local people also can work well with the Chinese workers through fluent communication.

\section{B. Focus on Professional and Technical Personnel Training}

The training of professional and technical personnel can be carried out from the following aspects:

1) Strengthen the training of talents in colleges, vocational and technical schools: Each professional training direction and target point to the need for professional training college should be reviewed. In order to cultivate the students tended to internationalization, the professional single school needs to increase the corresponding professional or professional training or broaden the original road according to the market demand and "One belt, one road" strategic [7]. Talent training should also target at international market and opportunities but stop in the domestic market, and make internationalization as general. It is important that during teach them professional knowledge at the same time will determine each person's employment goals. Learning skills and employment will be linked early and learn to understand language culture well. This is especially important for technical talents, so they should pay attention to combined with the enterprise practice work during the study, and enhance students' practical ability so when students are out of school can successfully accept social work rather than face graduation unemployment. This is 
benefit whether for the employment prospects of themselves or the needs of the state personnel.

2) Encourage existing personnel training of society and enterprise: In addition to develop talents in schools, it is also important to encourage existing personnel to accept training and upgrading. Because they have rich work experiences and can finish works smoothly, so work efficiency can be higher than others. Therefore, it needs the government, enterprises and other relevant groups to ensure the rational use of these talents. Due to the politics, economy and culture of countries along "One belt, one road" are different from China, and the degree of development in all aspects are in a low level, so there will be a lot of not adapt even unsafe factors, thus the talents who want to participate in the construction of the strategy should be cherished and give great incentives.

\section{CONCLUSIONS}

It is imperative to develop the talents for "One belt, one road", but which is more important, the professional talent or inter-disciplinary talents? The paper put forward corresponding multiple channels strategic thinking of talents cultivation through analyze such talents needed by "One belt, one road" deeply as language talent, professional talent, transnational management talents, academic research and communicate talents, traditional culture transmit talents, aimed to supplement necessary theory knowledge for our great strategy "One belt, one road". It is believed that our personnel training will not only provide better services for the strategy but also adjust the domestic talent cultivation mode, promote employment rate and improve talent utilization through these flexible adjustments based on the above aspects and later practices and pay greatly attention to practical needs.

\section{ACKNOWLEDGMENT}

After the study and research in nearly a year, my knowledge structure and ability of scientific research are to be a new level. And more important, the whole quality has been improved. Thanks to my professor Ma to profound teachings and enthusiasm to encourage me. On the occasion of the successful completion of the occasion, firstly, I have to express deep respect to my respected tutor teacher Ma. At the same time, thanks to basic curriculum professors who have taught me extensive knowledge, and thanks to the teacher in charge Jiang's patient guidance. Their inculcate make my butt down graduate study is full of enthusiasm and expectations.

\section{REFERENCE}

[1] J.B. Yang, "Research on the values education of college students majoring in navigation," Dalian Maritime University, doctoral dissertation, March 2013.

[2] X.F. Chen, "Innovative synergy talents Training mode of Higher Vocational Colleges under the background of "One belt, one road"," Chinese occupation technology education, April 2016.

[3] C.H. Long, "Talent training strategy from the perspective of excellent foreign legal knowledge under "One Belt, One Road"," 2015, pp. 30-33.

[4] Q. Shen, "Great Lack of Talent Report --- Small Languages, Between Hot and Cold," Guangming Daily, December 2014.

[5] G.P. Zhou, and Y. Kan, "Talent Support and Education Path of "One belt, one road" Strategy," Education Research, October 2015.

[6] X.N. Gu, "Talent Demand and the Reform of Business English Teaching for "The Belt and Road"," Journal of Economic Research, October 2015.

[7] European Council on Foreign Relations "One Belt, One Road" : China's Great Leap Outward. London: European Council on Foreign Relations, February 2015. 